\title{
The treatment of severe dystonia in children and adults
}

\author{
CD MARSDEN, M-H MARION, N QUINN
}

From the University Department of Neurology, Institute of Psychiatry, and King's College Hospital Medical School, London, UK

SUMMARY Twenty-three children (aged less than 18 years) and 17 adults with severe widespread dystonia were treated with high doses of benzhexol (up to $130 \mathrm{mg}$ daily introduced slowly over many weeks). Children tolerated higher doses (median $30 \mathrm{mg} /$ day) than adults (median $20 \mathrm{mg}$ / day). $52 \%$ of the children gained useful benefit, many (43\%) without unwanted side effects. Such an approach was less successful in adults; $41 \%$ gained benefit, but only $35 \%$ had no side effects. Twelve adults with severe axial dystonia, and two children with life-threatening generalised dystonia were treated with a combination of a low constant dose of tetrabenazine to which were added pimozide and benzhexol as necessary. The dose of tetrabenazine was aimed at $75 \mathrm{mg}$ daily; pimozide was increased ( 6 to $25 \mathrm{mg} /$ day) until the dystonia was relieved or Parkinsonism and other side-effects prevented further increments; if necessary benzhexol (6 to $30 \mathrm{mg} / \mathrm{day}$ ) then was added to control side-effects and to provide additional benefit. $75 \%$ of the adults with severe axial dystonia, and one of the two children with life threatening generalised dystonia gained useful benefit from this regime. It is concluded that high dose benzhexol is the present first treatment of choice for children with severe dystonia, and is worth a try in adults but with less expectation of success. When benzhexol treatment alone fails in adults with severe disabling axial dystonia, or in children with life-threatening generalised dystonia, combined therapy with tetrabenazine, pimozide and benzhexol may give valuable symptomatic relief.

The treatment of the syndrome of torsion dystonia is very difficult. The problem is that patients with this disorder do not show any consistent pharmacological response to the many different categories of drugs that have been tried.' A minority of patients have benefited from carbamazepine, levodopa or dopamine antagonists, anticholinergic drugs or benzodiazepines, but it has proved impossible to predict which patients will be helped by which drugs, and many are not helped at all by conventional drug therapy.

Over the years, we have gradually evolved a plan for management of patients with severe torsion dystonia, and the results of this approach are the subject of the present report.

In 1979, Fahn and Marsden instituted a doubleblind placebo control trial of benzhexol (trihexi-

Address for reprint requests: Prof CD Marsden, Institute of Psychiatry, de Crespigny Park, London SE5 8AF, UK.

Received 9 May 1984. Accepted 11 June 1984 phenidyl) (Artane), up to $30 \mathrm{mg}$ daily in severe dystonia. The results (to be published elsewhere) were encouraging and Fahn had suggested increasing the dose further to see how much more benefit could be obtained. Fahn's results with high dose benzhexol ${ }^{2}$ have been published, and we report here our own parallel studies with this approach to the treatment of severe dystonia. Both Fahn's and our own experience have suggested that adults tolerate anticholinergic less well than children, and achieve less benefit. For this reason, one of us (CDM) has devised a combination drug regime from the management of severely disabling axial dystonia in adults, the results of which also are reported.

\section{Patients and methods}

High dose benzhexol treatment in children and adults Increasing doses of benzhexol were administered to 23 children and 17 adults with severe segmental, hemi-, multifocal or generalised dystonia. (For the purposes of classification, the body is divided into separate focal areas, 
the head and neck, the trunk, each arm and each leg. Segmental refers to dystonia affecting two or more adjacent focal areas but sparing the legs, hemi-dystonia affects the arm and leg on the same side, multifocal refers to dystonia affecting two or more separate focal areas, and generalised refers to widespread dystonia involving the legs and other areas.)

Benzhexol was started in a dose of 2 to $2.5 \mathrm{mg}$ once or twice daily, and increased thereafter by increments of 2 to $2.5 \mathrm{mg}$ per day at weekly intervals until either the dystonia was controlled adequately, or side effects appeared. If side affects were disabling, the dose was reduced till they remitted, and was held at that level for a month or so, before attempting to increase the dose further. Not every patient has yet reached the maximum tolerable dose, and the upper limit reached so far $(130 \mathrm{mg} /$ day $)$ may yet be exceeded.

In the early stages a few patients were treated with orphenadrine rather than benzhexol (three children and two adults). For estimates of anticholinergic dose, that of orphenadrine has been divided by a factor of 10 to give the equivalent benzhexol dosage.

Children: (Aged less than 18 years at start of benzhexol therapy)

Twenty-three children or adolescents have been treated with high dose benzhexol therapy. Their mean age of onset of dystonia was $7 \cdot 7$ years (range 4 to 14 ), and their mean age at start of benzhexol treatment was 12.8 years (range 6 to 18 years). The aetiology, distribution and severity of their dystonia is shown in table 1 . Three patients were Jewish, one coming from a family with autosomal recessive inheritance, the other two being sporadic cases. There were three other patients from families with autosomal recessive inheritance, and one patient from a family with apparent autosomal dominant inheritance. Three of the children had had stereotaxic surgery (bilateral in 1, unilateral in 2).

Adults: (Aged 18 or more years at start of benzhexol therapy)
Seventeen adults have been treated with high dose benzhexol therapy. Their mean age of onset of dystonia was 23.0 years (range 5 to 58 ), and their mean age at the start of benzhexol treatment was 37.7 years (range 22 to 59). The aetiology, distribution and severity of their dystonia is shown in table 1 . One patient was Jewish, from a family with autosomal recessive inheritance, and there were two other non-Jewish patients with this mode of inheritance. None of the adult patients had had stereotaxic surgery.

This patient group consists only of individuals with extensive segmental, hemi-, or generalised dystonia, and excludes our experience with the focal dystonias (cranial dystonia or Meige's disease or Brueghel's syndrome, spasmodic torticollis and writers' cramp), which will be referred to in the Discussion.

\section{Combined (tetrabenazine, pimozide and anticholinergic) treatment of severe axial dystonia in adults}

Our treatment of these severely disabled patients has evolved over the years. Initially, tetrabenazine alone was employed, but the doses required to improve dystonia caused unacceptable side effects, particularly depression. Tetrabenazine prevents storage and depletes the brain of all the monoamines, dopamine, noradrenaline and serotonin. ${ }^{4}$ Depression might have been due to depletion of noradrenaline and/or serotonin, so it was decided to reduce the dose of tetrabenazine to $75 \mathrm{mg}$ daily, and add a selective dopamine receptor antagonist, usually pimozide, which has a relatively pure action on dopamine receptors. ${ }^{5}$ Pimozide was added in an initial daily dose of $2 \mathrm{mg}$ mane, and was increased thereafter by $2 \mathrm{mg}$ per day at approximately weekly intervals, until dystonia was controlled adequately, or unacceptable Parkinsonism was induced. At this point, an anticholinergic drug, benzhexol in nearly all cases, was added and the dose was increased until Parkinsonism was controlled. If dystonia was still disabling on this regime, further attempts were made to increase the dose of pimozide and/or benzhexol as far as possible.

Twelve adults with severe axial torsion dystonia were

Table 1 Aetiology, distribution and severity of dystonia in patients treated with high dose benzhexol therapy

\begin{tabular}{|c|c|c|}
\hline & $\begin{array}{l}\text { Children } \\
\text { (aged less than } 18 \text { years at start } \\
\text { of therapy) }\end{array}$ & $\begin{array}{l}\text { Adults } \\
\text { (aged } 18 \text { or more years at start } \\
\text { of therapy) }\end{array}$ \\
\hline $\begin{array}{l}\text { Number } \\
\text { Aetiology }\end{array}$ & 23 & 17 \\
\hline Idiopathic (primary) dsytonia & 18 & 14 \\
\hline Sporadic & 13 & 11 \\
\hline Autosomal dominant & 1 & 0 \\
\hline Autosomal recessive & 4 & 3 \\
\hline Symptomatic (secondary) dystonia & 5 & 3 \\
\hline & Delayed onset ${ }^{3}$ & Post-traumatic \\
\hline & Kernicterus & Encephalitis \\
\hline & Extradural haematoma & Meningitis \\
\hline & Encephalitis & \\
\hline \multicolumn{3}{|l|}{ Distribution } \\
\hline Segmental & 6 & 9 \\
\hline Hemi & 4 & 1 \\
\hline Multifocal & 1 & 0 \\
\hline Generalised & 12 & 7 \\
\hline \multicolumn{3}{|l|}{ Severity } \\
\hline Mild disability & 0 & 3 \\
\hline Moderate disability, but active & 14 & 9 \\
\hline Chair or bed-bound & 9 & 5 \\
\hline
\end{tabular}


treated in this manner. Their mean age of onset of dystonia was 34.4 years (range 3 to 54). Nine of the 12 patients had idiopathic (primary) dystonia; in one patient the illness appeared to be inherited as an autosomal dominant trait, but none of the patients was Jewish. Three patients had symptomatic (secondary) dystonia, due to chronic neuroleptic therapy in two (tardive dystonia ${ }^{6}$ ). and encephalitis in one. Two patients had had previous bilateral stereotaxic surgery. Nine of these patients had severe, forceful uncomfortable and sometimes painful axial dystonic spasms rendering them chair or bed-bound. The three other patients had similar severe axial dystonia, but could walk. The axial dystonia consisted of extensor spasms of neck and trunk in five cases, flexor spasms of neck and trunk in five cases, and lateral scoliotic spasms in the remaining two. In five of the 12 cases the dystonic spasms were strikingly jerky, looking myoclonic (myoclonic dystonia ${ }^{7}$ ).

\section{Combined treatment in children}

Following our experience with the use of combined tetrabenazine, pimozide and benzhexol therapy in adults, we have empolyed the same strategy to treat two children with desperate dystonia. One, a 12-year-old boy, with onset of sporadic idiopathic progressive generalised dystonia at 5 years, was referred under sedation because of such severe dystonic spasms that he had become exhausted with signs of incipient cardiac failure and gastric bleeding. He required paralysis and artificial ventilation, and eventually a tracheostomy, for 2 weeks, while combined treatment was instituted. The other child, a 15 -year-old boy with onset of sporadic idiopathic progressive generalised dystonia at 7 years, was bed-bound, anarthric and dysphagic, and in considerable pain due to severe dystonic spasms.

\section{Results}

High dose benzhexol treatment in children (table 2) Eleven of the 23 children (52\%) gained definite
$(2+)$, considerable $(3+)$ or dramatic $(4+)$ benefit from this treatment. One 17-year-old girl chairbound because of apparently fixed dystonia of both legs returned to normal walking $(4+$ benefit) on $78 \mathrm{mg}$ benzhexol daily. One 17 -year-old boy dysarthric and unable to swallow without pushing the food down his throat, and with a disabling dystonic writers' cramp, regained intelligible speech and nearly normal swallowing and writing $(3+$ benefit) on $65 \mathrm{mg}$ benzhexol daily. A 17-year-old boy with torticollis and severe arm dystonia returned to competitive cricket and squash ( $3+$ benefit) on $45 \mathrm{mg}$ benzhexol daily. An 18-year-old boy unable to read or write because of torticollis and graphospasm returned to normal college activities ( $3+$ benefit) on $30 \mathrm{mg}$ daily. One 15-year-old boy severely disabled by generalised dystonia returned to normal schooling.

Improvement was independent of age of onset $(0$ to $1+$ benefit, mean $7 \cdot 1$ years; $2+$ to $4+$ benefit, mean 8.3 years), age at starting therapy ( 0 to $1+$, mean 11.4 years, $2+$ to $4+$, mean 13.7 years), severity of dystonia at start of therapy $(0$ to $1+, 7$ of 14 with moderate and four of nine with severe disability), or aetiological diagnosis. Seven of 13 with sporadic idiopathic (primary) dystonia, three of five with familial idiopathic (primary) dystonia, and two of five with symptomatic (secondary) dystonia showed definite to dramatic $(2+$ to $4+)$ improvement. None of these factors distinguished between those with considerable or dramatic benefit $(3+$ or $4+)$, and those with lesser degrees of benefit ( 0 to $2+)$. None of the three children who had had previous stereotaxic surgery showed any benefit.

Improvement appeared after some weeks or months of treatment. The extent of improvement

Table 2 Response to high dose benzhexol treatment of severe dystonia in children and adults

\begin{tabular}{|c|c|c|}
\hline & $\begin{array}{l}\text { Children } \\
\text { (23) }\end{array}$ & $\begin{array}{l}\text { Adults } \\
\text { (17) }\end{array}$ \\
\hline $\begin{array}{l}\text { Degree of benefit } \\
0 \text { : No benefit } \\
\text { 1+: Slight, but insignificant } \\
2+: \text { Definite, but still disabled } \\
3+: \text { Considerable, but dystonia still evident } \\
4+: \text { Dramatic, no obvious dystonia } \\
\text { Benefit } 0 \text { to } 1+ \\
2 \text { to } 4+\end{array}$ & $\begin{array}{l}9 \\
2 \\
7 \\
4 \\
1 \\
11 / 23(48 \%) \\
12 / 23(52 \%)\end{array}$ & $\begin{array}{l}8 \\
2 \\
6 \\
0 \\
1 \\
10 / 17(59 \%) \\
7 / 17(41 \%)\end{array}$ \\
\hline $\begin{array}{l}\text { Duration of therapy (months) } \\
\text { Mean } \\
\text { (Range) } \\
\text { Median } \\
\text { (quartile) } \\
\text { Treated for } 6 \text { months or more }\end{array}$ & $\begin{array}{l}22 \cdot 4 \\
(2 \text { to } 84) \\
12 \\
(6-24) \\
22 \text { of } 23\end{array}$ & $\begin{array}{l}29 \cdot 6 \\
(1-144) \\
6 \\
(5-24) \\
13 \text { of } 23\end{array}$ \\
\hline $\begin{array}{l}\text { Final dose of benzhexol (mg/day) } \\
\text { Mean } \\
\text { (Range) } \\
\text { Median } \\
\text { (quartile) }\end{array}$ & $\begin{array}{l}31 \cdot 6 \\
(6 \text { to } 78) \\
30 \cdot 0 \\
(15-36)\end{array}$ & $\begin{array}{l}36 \cdot 1 \\
(4 \text { to } 130) \\
20 \cdot 0 \\
(7 \cdot 5-30)\end{array}$ \\
\hline
\end{tabular}

${ }^{*}$ Scale modified from Fahn. ${ }^{2}$ 
Table 3 Unwanted side effects during high dose benzhexol treatment

\begin{tabular}{lll}
\hline & $\begin{array}{l}\text { Children } \\
(23)\end{array}$ & $\begin{array}{l}\text { Adults } \\
(17)\end{array}$ \\
\hline $\begin{array}{lll}\text { No side effects } \\
\text { Peripheral side effects }\end{array}$ & $10(43 \%)$ & $6(35 \%)$ \\
$\quad$ Dry mouth & 4 & 8 \\
$\quad$ Blurred vision & 4 & 6 \\
$\quad$ Urinary difficulty & 1 & 0 \\
Central side effects & 5 & 2 \\
$\quad$ Drowsy & 3 & 2 \\
$\quad$ Forgetful & 2 & 3 \\
Hyperkinetic & 1 & 0 \\
$\quad$ Hallucinations & Some patients complained of more than one side effect. \\
\hline
\end{tabular}

appeared to depend upon the dose of benzhexol achieved. Those with little benefit $(0$ to $1+)$ took a mean of $22.3 \mathrm{mg} /$ day, while those with definite to dramatic benefit $(2+$ to $4+)$ took a mean of $40.3 \mathrm{mg} /$ day. However, there was great individual variability in the dose required for benefit. Some patients showed improvement on as little as $6 \mathrm{mg} /$ day, while others required more than 30 to $50 \mathrm{mg}$ per day before any change was evident. The lower dose amongst those with little or no improvement $(0$ to $1+$ ) was not the result of a greater prevalence of side effects in this group (table 3 ). Ten of the 23 children, including four of 11 with little or no benefit, had no side effects on a mean dose of $28.9 \mathrm{mg}$ benzhexol daily. The 13 children with side effects, including seven with little or no benefit, were taking a mean dose of $33.8 \mathrm{mg}$ benzhexol daily. Of those 11 children who failed to improve $(0$ to $1+)$, five were taking $16 \mathrm{mg}$ or less benzhexol daily. Of the 12 who did gain definite to dramatic improvement $(2+$ to $4+$ ), only three were taking less than $30 \mathrm{mg}$ benzhexol daily, six were taking 30 to $60 \mathrm{mg}$ daily, and three were taking 65 to $78 \mathrm{mg}$ daily. It may be that further gains will be achieved by increasing the dose in those with little or no improvement.

Sixteen of the 23 children continued on benzhexol treatment. The drug was stopped in seven cases because of intolerable side-effects (4) or lack of benefit (3).

\section{High dose benzhexol treatment in adults (table 2)}

Seven of the 17 adults $(41 \%)$ gained definite $(2+)$, or dramatic $(4+)$ benefit from this treatment. One 32-year-old man with right hemi-dystonia greatly impairing his gait returned to normal walking. In the remaining six patients, the gains were less impressive, but still definite $(2+)$.

Improvement was independent of age of onset $(0$ to $1+$, mean 22.9 years; $2+$ to $4+$, mean 23.1 years), age at starting therapy ( 0 to $1+$, mean $41 \cdot 1$ years; $2+$ to $4+$, mean 32.8 years), severity of dys- tonia at start of therapy ( 0 to $1+$, one of three with mild disability, five of nine with moderate disability, and four of five with severe disability; $2+$ to $4+$, two of three with slight, four of nine with moderate, and one of five with severe disability), or aetiological diagnosis. Five of 11 with sporadic idiopathic (primary) dystonia, one of three with familial idiopathic (primary) dsytonia, and one of three with symptomatic (secondary) dystonia showed definite or dramatic $(2+$ to $4+)$ improvment.

Improvement again took time to appear, and depended upon the dose of benzhexol achieved. Those with little or no benefit ( 0 to $1+)$ took a mean of $22.2 \mathrm{mg}$ benzhexol/day, while those with definite or dramatic benefit $(2+$ to $4+)$ took a mean of $56.1 \mathrm{mg} /$ day. The lower dose in those with little or no improvement again was not imposed by side effects. Six of the 17 adults, including five of the 10 with little or no benefit, had no side effects on a mean dose of $26 \cdot 1$ on benzhexol daily. The 11 adults with side effects, including five with little or no benefit, took a mean dose of $44.3 \mathrm{mg}$ daily. Of those 10 adults who failed to improve $(0$ to $1+)$, six were taking $15 \mathrm{mg}$ benzhexol daily. Of the seven who did gain definite to dramatic improvement $(2+$ to $4+)$, three were taking less than $30 \mathrm{mg}$ benzhexol daily, and one each took $30,75,120$ and $130 \mathrm{mg}$ daily respectively.

Only seven of the 17 patients continued on benzhexol treatment. The drug was stopped in 10 cases because of intolerable side-effects (5) or lack of benefit (5).

\section{Combined (tetrabenazine, pimozide and benzhexol)}

treatment of severe axial dystonia in adults

In all 12 cases, tetrabenazine was introduced first. To start with a relatively high dose was employed; five patients took 125 to $150 \mathrm{mg}$ daily, while seven patients took 75 to $100 \mathrm{mg}$ daily. Unfortunately it was soon learnt that high doses of tetrabenazine were associated with an unacceptable prevalence of depression. Three patients had to stop the drug because of this side effect and two others had to reduce the dose. At the time of their depression these five patients were taking a mean of $130 \mathrm{mg}$ of tetrabenazine daily. Of the nine patients who continued on tetrabenazine, after dosage adjustment, their mean dose was $90 \mathrm{mg} /$ day, which they have continued for between 1 to 144 months (mean 22). Six of these 9 patients were taking $75 \mathrm{mg} /$ day or less.

Pimozide then was added to tetrabenazine, in optimum dosage, in seven cases. The initial dose usually was $2 \mathrm{mg}$ mane increasing thereafter by $2 \mathrm{mg}$ at approximately weekly intervals, until side effects occurred or adequate therapeutic response was achieved. The final mean dose of pimozide used in 
these seven patients was $11 \mathrm{mg} /$ day (range 6 to $25 \mathrm{mg}$ ), as a single morning dose, which they have continued for between 1 to 36 months (mean 12).

Anticholinergic drugs were added to combined tetrabenazine/pimozide treatment in six patients, or to tetrabenazine alone in four other patients. Benzhexol was used in 10 of these patients, and orphenadrine in the remaining case. As with pimozide, benzhexol was added in a small dose and gradually increased every three to five days. The final mean dose of benzhexol achieved in these patients was $16 \mathrm{mg} /$ day (range 6 to $30 \mathrm{mg}$ ), which they have continued for between 1 to 144 months (mean 31.5).

One patient, intolerant of tetrabenazine, was managed on chlorpromazine alone ( $750 \mathrm{mg}$ daily), which he has continued for 132 months.

On their final optimal regime, two of the patients showed a dramatic improvement $(4+)$ in their dystonia, four showed a marked improvement $(3+)$, three showed a moderate improvement $(2+)$, one showed a slight improvement $(1+)$, and two showed no improvement $(0)$. The nine patients $(75 \%)$ showing moderate to dramatic improvement have continued on their drug therapy. Three patients showing slight or no improvement have stopped taking this form of treatment. Those who failed to respond included one patient with tardive dystonia, but another patient with tardive dystonia showed a moderate improvement. Another patient managed on tetrabenazine and benzhexol without pimozide, showed no improvement, and her drugs were stopped because of severe depression and the emergence of extrapyramidal side effects. A further patient with idiopathic (primary) dystonia, who has had previous bilateral stereotaxic surgery, showed only slight improvement, and could not tolerate the combination because of blurred vision and urinary difficulties, as well as Parkinsonism. The other patient who had had previous bilateral stereotaxic surgery showed moderate improvement, but still exhibited obvious dystonia $(2+)$.

Amongst those nine patients who continued on treatment, five were taking combined tetrabenazine, pimozide and benzhexol, two were taking tetrabenazine and benzhexol, one was taking tetrabenazine and pimozide, and one was taking chlorpromazine alone. Amongst these nine patients, three had evident Parkinsonism, but of a severity insufficient to cause disability; one complained of akathisia, two had anticholinergic side effects, and one exhibited some drowsiness. None of these side effects were sufficient to warrant discontinuation of treatment.

The response to treatment in many of these nine patients has been remarkable. Seven of the nine were bed or chair-bound, with severe and often painful spasms of axial muscles. The remaining two patients could not sit comfortably because of similar axial dystonia. Eight of the nine patients now on treatment can walk and sit comfortably. The remaining patient has shown less improvement, but he is the individual suffering from symptomatic postencephalitic dsytonia.

\section{Combined (tetrabenazine, pimozide and benzhexol)} treatment of life-threatening dystonia in children

The first 12-year-old child, paralysed and ventilated to relieve devastating generalised idiopathic dystonia, was started on tetrabenazine ( $75 \mathrm{mg}$ daily), with increasing pimozide (up to $12 \mathrm{mg}$ daily), to which increasing benzhexol was added after a fortnight. After 2 weeks on this treatment, having reached $12 \mathrm{mg}$ daily of benzhexol, ventilation could be discountinued, and the tracheostomy was closed. After a further two weeks during which the benzhexol was increased to $18 \mathrm{mg}$ daily, he was able to walk home, albeit still with obvious generalised dystonia.

The other severely affected 15 -year-old boy was treated with tetrabenazine ( $75 \mathrm{mg}$ daily), and benzhexol ( $30 \mathrm{mg}$ daily), but the addition of pimozide (1 mg daily) provoked a super-added acute dystonic reaction, so pimozide was discontinued. Subsequent treatment with tetrabenazine and benzhexol was of no value, so the drugs were withdrawn. He remained severely disabled and bed-bound.

\section{Discussion}

High dose benzhexol treatment in children and adults The results of the present study are in broad agreement with those reported by Fahn ${ }^{2}$ (table 4). Combining the two studies, 26 of $46(56 \%)$ children, aged less than 18 years at the start of therapy, gained significant benefit from benzhexol therapy. This was of moderate degree, with residual disabling dystonia, in 12 of 46 ; considerable, but dystonia still evident in nine of 46; and dramatic, with no obvious residual dystonia, in five of 46 .

Children could tolerate high doese of benzhexol, up to $80 \mathrm{mg} /$ day in Fahn's study, ${ }^{2}$ and up to $78 \mathrm{mg}$ / day in the present investigation, with a suprisingly low incidence of dose-limiting side effects, provided dosage escalation was undertaken very slowly. Despite concern over the effects of such high doses of benzhexol on learning and other higher mental functions, schooling appears to have proceeded normally in our children once optimum dosage had been established. Nevertheless, this remains a cause of concern, and all the children are being monitored for possible adverse effects of high dose benzhexol 
Table 4 Comparison of results of high dose anticholinergic drug treatment in studies of Fahn ${ }^{2}$ and reported here

\begin{tabular}{|c|c|c|c|c|}
\hline & \multicolumn{2}{|c|}{ Children } & \multicolumn{2}{|l|}{ Adults } \\
\hline & Fahn & Present study & Fahn & Present study \\
\hline $\begin{array}{l}\text { Number of patients } \\
\text { Mean of median dose (range) } \dagger \\
\text { (mg/day) } \\
\text { Little or no benefu } \\
\text { Definite to dramatic benefit } \\
(2+\text { to } 4+) \\
\text { Side effects }\end{array}$ & $\begin{array}{l}23 \\
41 \\
(8-80) \\
9 \\
14 \\
(61 \%) \\
?\end{array}$ & $\begin{array}{l}23 \\
30 \\
(6-78) \\
11 \\
12 \\
(52 \%) \\
13 \\
(57 \%)\end{array}$ & $\begin{array}{l}28 \\
24 \\
17 \\
11 \\
(39 \%) \\
?\end{array}$ & $\begin{array}{l}17 \\
20 \\
(4-130) \\
10 \\
7 \\
(41 \%) \\
11 \\
(67 \%)\end{array}$ \\
\hline
\end{tabular}

*Only those patients with generalised, segmental or hemi-dystonia studied by Fahn² are considered.

†Mean doses are quoted from Fahn, ${ }^{2}$ and median doses from the present study. The mean dose quoted by Fahn ${ }^{2}$ is only for those 20 children who continued treatment for 1 year or more.

therapy on intellectual function. The recent emphasis on involvement of cholinergic mechanisms in memory ${ }^{10}$ and dementia ${ }^{11}$ highlights the potental problems of this form of treatment. For this reason, we reserve high dose anticholinergic therapy for those children who are severely disabled by their dystonia. We do not increase the dose of benzhexol higher than that required to relieve the most disabling aspects of the illness. The aim is not to abolish dystonia, but to restore function, as far as possible, with the lowest dose of benzhexol. How high benzhexol dosage can be increased is not yet known. What has become apparent is that side effects can be avoided by a very gradual build-up and, if they occur, then decreasing the dose for a while may allow subsequent increases without their reappearance.

Similar treatment in adults has been less successful. Combining the results of Fahn's study ${ }^{2}$ and those of the present investigation show that 18 of 45 $(40 \%)$ of adults with generalised, segmental or hemi-dystonia gained useful benefit. The response was moderate in 11 of 45 ; considerable in five of 45 ; and dramatic in two of 45 . Thus, in adults only seven of $45(16 \%)$ gained considerable or dramatic benefit, in contrast to 14 of $46(30 \%)$ children. Adults tolerated high dose anticholinergic treatment less well than children. Some $50 \%$ of Fahn's total number of 52 adult patients with dystonia had to stop therapy because of side effects in contrast to some $13 \%$ of his 23 children. Corresponding figures in the present study were $30 \%$ of adults and $17 \%$ of children. These problems are reflected in the lower dose of benzhexol achieved in adults (median $20 \mathrm{mg} /$ day), in contrast to children (median $30 \mathrm{mg}$ / day) in the present study. The difference is even more striking in the case of anticholinergic treatment of the focal dystonias (table 5). Fahn ${ }^{2}$ presents data of 16 patients with spasmodic torticollis and seven patients with cranial dystonia, to which we can add 24 patients with spasmodic torticollis (unpub-
Table 5 Comparison of anticholinergic treatment of spasmodic torticollis, cranial dystonia and writers' cramp

\begin{tabular}{|c|c|c|}
\hline & Fahn ${ }^{2}$ & Our studies \\
\hline \multicolumn{3}{|l|}{ Spasmodic torticollis } \\
\hline Number of patients & 16 & $24^{*}$ \\
\hline $\begin{array}{l}\text { Little or no benefit } \\
(0 \text { to } 1+)\end{array}$ & 10 & 13 \\
\hline $\begin{array}{l}\text { Definite to dramatic benefit } \\
(2+\text { to } 4+)\end{array}$ & $\stackrel{6}{(38 \%)}$ & $\begin{array}{l}11 \\
(46 \%)\end{array}$ \\
\hline \multicolumn{3}{|l|}{ Cranial dystonia } \\
\hline Number of patients & 7 & $25 \dagger$ \\
\hline $\begin{array}{l}\text { Little or no benefit } \\
(0 \text { to } 1+)\end{array}$ & 4 & 22 \\
\hline $\begin{array}{l}\text { Definite to dramatic benefit } \\
(2+\text { to } 4+)\end{array}$ & $\stackrel{3}{(43 \%)}$ & $\stackrel{3}{(12 \%)}$ \\
\hline \multicolumn{3}{|l|}{ Writers' cramp } \\
\hline Number of patients & & 15 \\
\hline $\begin{array}{l}\text { Little or no benefit } \\
\text { ( } 0 \text { to } 1+)\end{array}$ & & 11 \\
\hline $\begin{array}{l}\text { Definite to dramatic benefit } \\
(2+\text { to } 4+)\end{array}$ & & $\begin{array}{c}4 \\
(27 \%)\end{array}$ \\
\hline
\end{tabular}

*Unpublished observation.

† Marsden et al ${ }^{8}$.

¥Sheehy and Marsden".

lished data), 25 patients with cranial dystonia ${ }^{8}$ and 15 patients with writers' cramp. ${ }^{9}$ Combining these various studies, only 17 of $40(42 \%)$ patients with spasmodic torticollis, six of $32(19 \%)$ with cranial dystonia, and four of $15(27 \%)$ with writers' cramp gained significant improvement.

Nevertheless, it is worth attempting a trial of benzhexol therapy in adult-onset dystonia, of whatever distribution, although expectation of failure and of side effects will be high. Indeed, it is our current practice to employ an anticholinergic drug as the first line of therapy in adult-onset dystonia, if disability justifies treatment and the risk of unwanted side effects. Most patients with spasmodic torticollis and cranial dystonia will opt for such a course of action, after discussion, but many with writers' cramp prefer to avoid drug treatment. We employ benzhexol, for we are comforable with its use and the dosage is easy to fractionate, but have 
no experience of the use of ethopropazine as advocated by Fahn. ${ }^{2}$

Combined therapy for severe disabling adult dystonia Because of the relative lack of success of anticholinergic therapy in adults with dystonia, we have employed combined tetrabenazine, pimozide and anticholinergic treatment in the severely disabled. We have used this approach particularly in those with severe axial dystonia, which commonly prevents sitting, walking and even sleeping. The results of this treatment have been encouraging. Threequarters of those managed in this way have responded to the extent of gaining independent comfortable mobility. The problem of intolerable side effects has been reduced, although not eliminated, by keeping the dose of tetrabenazine low. In another study of 35 patients with dystonia treated with tetrabenazine (mean dose $104 \mathrm{mg} /$ day; range 25-200), 11 were unable to tolerate the drug, and some $80 \%$ reported undesirable side effects. ${ }^{12}$ Particularly troublesome were drowsiness, akathisia and depression. Nine patients benefited from the drug, but only two showed marked improvement. Jankovic ${ }^{13}$ recently reported more favourable results with tetrabenazine in dystonia, as had Swash et al, ${ }^{14}$ previously, but many of the patients in these studies experienced similar side effects.

The frequency and severity of the side effects of tetrabenazine may reflect its ability to deplete all three monoamine neurotransmitters (dopamine, noradrenaline and serotonin) and its effects on other neurotransmitters such as acetylcholine and certain amino acids. ${ }^{15}$ For this reason, we decreased the dose, aiming to give no more than $75 \mathrm{mg}$ daily, and added a selective post-synaptic dopamine receptor antagonist, pimozide. Pimozide is a potent dopamine antagonist with little effect on other neurotransmitter receptors, as judged by ligand binding studies (unpublished observations). Tetrabenazine recently has also been shown to have post-synaptic antagonist action on dopamine receptors, ${ }^{16}$ but this is weak; it inhibits ${ }^{3} \mathrm{H}$-spiperone binding to striatal homogenates in micromolar contractions, whereas pimozide is effective in the nanomolar range. The combination of tetrabenazine and pimozide may be expected to effectively reduce dopaminergic action in the brain, by a combination of pre-synaptic action by depletion of dopamine stores and post-synaptic receptor blockade. Fog and Pakkenberg ${ }^{17}$ have shown that the combination is effective in controlling chorea in Huntington's disease. Our present studies indicate that it also can be of benefit in severe axial dystonia in adults and occasionally in disastrous generalised dystonia in children. However, frequently the doses of tetra- benazine and pimozide required to control dystonia cause disabling Parkinsonism. For this reason, we often added the anticholinergic, benzhexol, which also benefits the dystonia. The art of this method of treatment is to titrate the pimozide and benzhexol, against the low fixed dose of tetrabenazine, to achieve the greatest relief of dystonia with the least Parkinsonism.

Combined tetrabenazine, pimozide and benzhexol therapy can be employed in children, but there are arguments against this line of treatment. Chronic dopamine antagonist therapy can produce disabling tardive disorders, including tardive dystonia. ${ }^{6}$ It seems unwise to use this therapy in children with dystonia, who face a lifetime of drug treatment. For this reason we prefer high dose anticholinergic therapy as the first line of treatment for childhood dystonia, and for adults with moderately disabling dystonia, reserving combined treatment for those disastrously affected by the illness.

We thank the many colleagues who have referred patients for treatment, and The Dystonia Foundation for financial support.

\section{References}

' Marsden CD. Treatment of torsion dystonia. In: Barbeau A, ed. Disorders of Movement. Lancaster: MTP Press, 1981:81-104.

${ }^{2}$ Fahn S. High dose anticholinergic therapy in dystonia. Neurology (NY) 1983;33:1255-61.

${ }^{3}$ Burke RE, Fahn S, Gold AP. Delayed-onset dystonia in patients with "static" encephalopathy. J Neurol Neurosurg Psychiatry 1980;43:789-97.

${ }^{4}$ Fuenmayor LD, Vogt M. Production of catalepsy and depletion of brain monoamine by a butyrophenone derivative. Br J Pharmacol 1979;67:115-22.

5 Pinder RM, Brogden RN, Sawyer PR, et al. Pimozide: A review of its pharmacological properties and therapeutic uses in psychiatry. Drugs 1976;12:1-40.

- Burke RE, Fahn S, Jankovic J, et al. Tardive dystonia: Late-onset and persistent dystonia caused by antipsychotic drugs. Neurology (NY) 1982;32:1335-46.

' Obeso JA, Rothwell JC, Lang AE, Marsden CD. Myoclonic dystonia. Neurology (NY) 1983;33:825-30.

${ }^{8}$ Marsden CD, Lang AE, Sheehy MP. Pharmacology of cranial dystonia. Neurology (NY) 1983;33:1100-1.

9 Sheehy MP, Marsden CD. Writers' cramp - a focal dystonia. Brain 1982;105:461-80.

${ }^{10}$ Crow TJ, Grove-White IG. An analysis of the learning deficit following hyoscine administration to man. $B r J$ Pharmacol 1973;49:322-7.

"Perry EK, Gibson PH, Blessed G, et al. Neurotransmitter enzyme abnormalities in senile dementia. J Neurol Sci 1977;34:247-65.

${ }^{12}$ Lang AE, Marsden CD. Alphamethylparatyrosine and tetrabenazine in movement disorders. Clin 
Neuropharmacol 1982;5:375-87.

13 Jankovic J. Treatment of hyperkinetic movement disorders with tetrabenazine: A double-blind cross-over study. Ann Neurol 1982;11:41-7.

${ }^{14}$ Swash M, Roberts AH, Zakko H, Heathfield KWG. Treatment of involuntary movement disorders with tetrabenazine. J Neurol Neurosurg Psychiatry 1972;35:186-91.

15 Lane JD, Smith JE, Shea PA, McBride WJ. Neurochem- ical changes following the administration of depleters of biogenic monoamines. Life Sci 1976;19:1663-8.

${ }^{16}$ Login IS, Cronin MJ, MacLeod RM. Tetrabenazine has properties of a dopamine receptor antagonist. Ann Neurol 1981;12:257-62.

${ }^{17}$ Fog R, Pakkenberg H. Combined nitoman-pimozide treatment of Huntington's chorea and other hyperkinetic syndromes. Acta Neurol Scand 1970;46:249 51. 